\title{
O LUGAR DO ENSINO DE HISTÓRIA NO BRASIL DA REDEMOCRATIZAÇÃO
}

\author{
THE PLACE OF THE TEACHING OF HISTORY IN THE \\ BRAZIL OF RE-DEMOCRATIZATION
}

Ana Paula Sampaio Caldeira ${ }^{1}$

\begin{abstract}
RESUMO: Para o campo da historiografia acadêmica no Brasil, a década de 1980 representou um momento de importante atividade intelectual e de produção de obras fundamentais para a renovação dos estudos históricos. Neste artigo, nos interrogamos sobre o significado que essa década teve para o ensino de história. Para respondermos a essa questão, analisaremos uma coleção didática específica, chamada Brasil Vivo, publicada na segunda metade da década de 1980. Ela nos servirá de fio condutor para compreendermos as demandas sociais e os anseios em torno do ensino de história neste contexto de redemocratização.
\end{abstract}

Palavras-chave: Ensino de História. Livro Didático. Redemocratização.

\begin{abstract}
For the field of academic historiography in Brazil the 1980s represented a moment of important intellectual activity and the production of fundamental works for the renovation of historic studies. In this article we ask ourselves about the meaning that this decade had for the teaching of history. To answer this question we analyze a specific didactic collection, called Brasil Vivo, published in the second half of the 1980s. It serves as a guidewire to understand the social demands and anxieties about the teaching of history in this context of re-democratization.
\end{abstract}

Keywords: Teaching of history. Textbook. Re-democratization.

\section{Introdução}

Dentre os estudiosos de um determinado tema ou campo de estudos, é bastante comum a elaboração de certos "balanços historiográficos", buscando identificar tendências, inovações e caminhos da produção historiográfica num dado momento. Algumas análises nesse sentido já foram elaboradas acerca dos trabalhos produzidos pelos historiadores nas duas últimas décadas do século $\mathrm{XX}$. A ideia de "crise", por exemplo, foi bastante utilizada como chave de entendimento para uma série de mudanças no campo da história e que traziam à

1 Professora do Departamento de História e do Programa de Pós-Graduação em História da Universidade Federal de Minas Gerais. 
tona debates sobre as questões relacionadas à temporalidade, à narrativa e à validade das análises estruturalistas. De acordo com autores como Revel (2009), Chartier (2002) e Dosse (2004), o que tivemos a partir dos anos 1980 foi a deterioração e decadência dos grandes modelos teóricos que visavam garantir um entendimento global do mundo sócio-histórico. Tal crítica teria favorecido a construção de diagnósticos que falavam em uma crise do tempo histórico e dos macromodelos explicativos sobre os quais se assentava, por exemplo, a história social francesa dos Annales. Assim, para esses autores, o que se colocava em questão naquele momento era a validade dos modelos funcionalistas, bem como certos pressupostos e noções sobre as quais os historiadores, há algumas décadas, construíam suas análises. Daí o diagnóstico de que a história vivia uma época de "crise", que seria agravada quando o próprio estatuto de cientificidade do conhecimento histórico, foi posto em questão com trabalhos como os de Hayden White (1992).

Apesar do diagnóstico de crise, algumas análises parecem estar de acordo com a ideia de que esse foi também um momento de intensa atividade intelectual, que levou os historiadores a percorrerem uma multiplicidade de caminhos de análise. De certa maneira, o conhecimento histórico parecia menos preocupado com a longa duração, as invariâncias, as generalizações e a objetividade e passou a atentar para aspectos do cotidiano, para as sensibilidades, a ação dos sujeitos históricos e os pontos de vista dos agentes sociais. Essa mudança pode ser percebida também no próprio vocabulário empregado nos trabalhos historiográficos, em que noções como experiência, negociação e práticas foram, aos poucos, ganhando espaço, deslocando outros termos até então muito empregados pelos historiadores, tais como classe, estrutura e ideologia (GOMES, 2004).

Quanto ao caso brasileiro, seria amplo o número de importantes trabalhos que poderiam ser lembrados neste quadro de renovação. Trabalhos estes que acabaram se transformando em livros de referência no campo historiográfico, justamente pelo caráter inovador de certas análises. ${ }^{2}$ Não é o caso de citá-los

\footnotetext{
2 Vale a pena ressaltar aqui alguns textos de balanço sobre a historiografia brasileira dos anos 1980 . É o caso, por exemplo de Vainfas (2009), Rago (1999), Gomes (2004) e Chalhoub e Silva (2009). Em artigo recentemente publicado, Sousa (2017) procura também pensar a abertura da historiografia brasileira no contexto de redemocratização do país.
} 
todos aqui, mas vale a pena lembrar como os estudos sobre a escravidão, a sociedade colonial, o movimento operário, a história do livro e da leitura ou sobre a história das mulheres foram temas e objetos decisivos neste contexto de renovação historiográfica, trazendo novas questões e atores sociais para o universo de preocupação dos historiadores. Além disso, abriram margem para análises mais preocupadas com as dinâmicas relacionais, o imaginário, os agenciamentos, os conflitos e a dimensão criativa e inventiva presente nas ações dos sujeitos históricos. ${ }^{3}$

Essa renovação certamente insere-se no movimento de criação e ampliação dos programas de pós-graduação no país. Como lembra Marieta de Moraes Ferreira, sem desconsiderar todas as perdas que os anos de ditadura militar trouxeram para as universidades e para a Educação Básica, é visível o crescimento das pós-graduações brasileiras a partir da década de 1970. No que se refere à Educação Básica, se o governo militar deu um passo atrás com a criação dos cursos de licenciatura em Estudos Sociais (que reuniam História, Geografia e Organização Social e Política do Brasil), nos quadros da universidade, o incremento dos programas de pós-graduação em história acabaram por fortalecer a pesquisa histórica no país. Por outro lado, ajudaram também, como lembra a própria autora, a agudizar a tensão, existente desde a criação dos primeiros cursos universitários de história, entre a pesquisa e a formação de professores para trabalhar na Educação Básica (FERREIRA, 2016).

Essas considerações iniciais nos pareceram necessárias para chegarmos a um diagnóstico que os autores citados já nos deixaram evidente: o de desenvolvimento dos estudos históricos por caminhos diversos, uns mais e outros menos profícuos, nas últimas décadas do século XX. Isso tanto no cenário internacional quanto nacional. No caso brasileiro, a ampliação dos cursos de graduação e de pós-graduação em história (FERREIRA, 2016; ROCHA; PACHECO, 2016), bem como das demandas pela divulgação do conhecimento histórico, aconteceu em meio a um momento de importantes mudanças políticas em função do processo de redemocratização que punha fim a duas décadas de um governo ditatorial. Apesar de nessa época o Brasil ter passado por uma intensa

3 A título de exemplo, algumas importantes referências nesse sentido são: GOMES (2005), DE Decca (1981), Samara (1989) e Souza (1986), dentre muitas outras obras que poderiam ser citadas. 
crise econômica, que muito contribuiu para caracterizar os anos 1980 como uma "década perdida" (QUADRAT, 2014), certos estudos já apontaram que, em termos de produção historiográfica e de desenvolvimento da pesquisa histórica no Brasil, esse momento não pode ser caracterizado com esse mesmo tom pessimista (FICO; POLITO, 1992).

Se a escrita da história produzida no interior das universidades parecia passar por um período de crescimento, para o ensino de história, o que teria representado a década de 1980? A noção de "ensino de história" é certamente muito larga e engloba muitas dimensões, instituições, espaços e agentes. Ao levantarmos essa questão, estamos nos referindo à história ensinada não nos cursos de graduação ou pós-graduação, mas àquela voltada para outro público, composto por crianças, jovens e adultos que frequentavam as escolas do país. Para essa história ensinada nos espaços escolares, poderíamos falar também de "incremento? A questão é certamente bastante ampla e o que propomos fazer aqui é uma reflexão em dois sentidos. Primeiramente, queremos nos interrogar sobre o lugar que a história, como conhecimento escolar, ocupou neste contexto de redemocratização dos anos 1980. Em seguida, gostaríamos de lançar algumas hipóteses acerca dos legados das reflexões e das demandas em torno do ensino de história naquele momento para as décadas posteriores. Assim, poderíamos dizer que as reflexões que fazemos neste texto têm um olho no passado e outro no presente. Isso porque a ideia de crise parece que voltou com força para o universo de reflexões dos historiadores, especialmente em função do contexto político em que vivemos hoje em termos nacionais e internacionais. ${ }^{4}$ Fala-se em crise das humanidades, da história, da escola e do ensino de história. Neste último caso, especialmente, esta crise nos leva a um quadro preocupante, que envolve, inclusive, uma série de incertezas quanto à garantia do ensino desta disciplina na Educação Básica. Neste sentido, nosso olhar se volta para um contexto não tão distante assim, o da redemocratização brasileira, pois nos parece que havia ali uma situação bastante distinta da que vivemos hoje: a de certo consenso em relação à relevância do ensino da história. Acreditamos que a

4 Um exemplo disso é o dossiê publicado em 2018 pela Revista Maracanan, intitulado "Crise na e da História: desafio à escrita e à reflexão crítica", organizado por Beatriz Vieira, Eduardo Felippe, Thiago Nicodemo. Trazendo artigos que abordam o conceito de crise sob diversos aspectos, também ali estão presentes algumas reflexões sobre a crise das humanidades, a crise da história disciplinar e a atuação do historiador público (AVILA, 2018; MAIA, 2018; NICOLAZZI, 2018). 
interrogação sobre o lugar do ensino de história nos anos 1980 é importante, pois pode nos oferecer elementos para entender como, em um intervalo de pouco mais de 30 anos, o discurso dominante na cena pública em torno da educação e do ensino de história tenha seguido outros rumos, muito mais próximo da "suspeita" do que da "confiança" depositada sobre a escola e sobre o conhecimento histórico.

Não teríamos, nesse texto, como nos amparar numa massa de dados ou em uma análise pormenorizada dos currículos, das práticas elaboradas pelos professores ou da produção didática desenvolvida a partir dos anos 1980. O caminho que seguiremos aqui é mais simples e certamente lacunar. Mas entendemos que ele pode nos levar a uma discussão inicial: escolhemos uma coleção de livros didáticos para analisar alguns aspectos que interessam diretamente para as questões propostas. Uma coleção apenas, dividida em dois volumes, mas bastante interessante, a nosso juízo, por ser representativa desse contexto de redemocratização pelo qual passava o país nos anos 1980 e dos anseios projetados sobre a educação - e, particularmente, sobre o ensino de história - naquele período.

\section{1. "Carroça abandonada" ou "carro alegre cheio de povo"?}

A coleção à qual nos referimos chama-se Brasil Vivo: uma nova história da nossa gente e foi produzida por três autores, dois deles professores e um arquiteto de formação: Chico Alencar, Marcus Venício Ribeiro e Claudius Ceccon. O primeiro deles é conhecido especialmente pela carreira política, tendo assumido diversos cargos legislativos quando foi membro do Partido dos Trabalhadores (PT) e, atualmente, como integrante do Partido Socialismo e Liberdade (Psol). À época de produção do livro, Chico Alencar era um professor de história formado pela Universidade Federal Fluminense (UFF), mestrando em educação, atuando no ensino básico. Chico Alencar e Marcus Venício Ribeiro já tinham experimentado uma parceria na elaboração de outro livro didático, chamado História da Sociedade Brasileira, que contou também com a participação de Lucia Carpi. Marcus Venício é formado em Ciências Sociais pela UFF e, quando da produção de Brasil Vivo, lecionava e pesquisava no Instituto de 
História Social Brasileira do Conjunto Universitário Candido Mendes, e cursava mestrado na UFF. Os textos deste livro didático são de autoria desses dois autores. A parte visual ficou aos cuidados de Claudius Ceccon, profissional formado em arquitetura, desenho industrial e urbanismo, atuante no campo do jornalismo e da educação popular.

A coleção foi publicada pela Vozes, uma editora sem tradição na produção de livros didáticos. O primeiro volume saiu em 1986 e o segundo, dois anos depois. O conteúdo dizia respeito exclusivamente à história do Brasil. Alguns temas ligados à história "geral" aparecem pontualmente, sempre com o intuito de inserir a história brasileira num quadro mais abrangente. A divisão das matérias se dá da seguinte forma: o primeiro volume abarca um período que vai do século XV ao final do Oitocentos. Toda a história republicana no país ficou a cargo do volume dois, que abarca o período da Primeira República até o tempo presente do próprio livro, tratando, portanto, do processo de redemocratização do país após as duas décadas de ditadura.

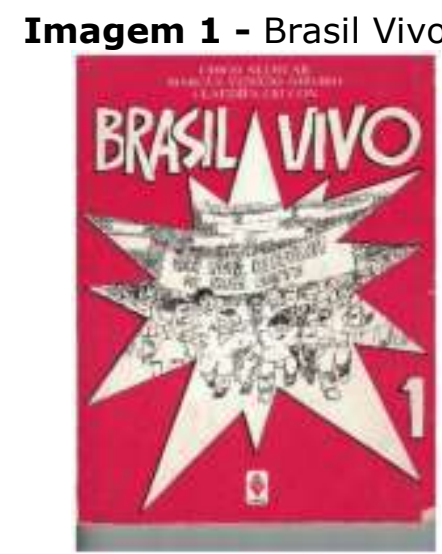

Fonte: Alencar, Ribeiro e Ceccon (1986-1988, v. 1)

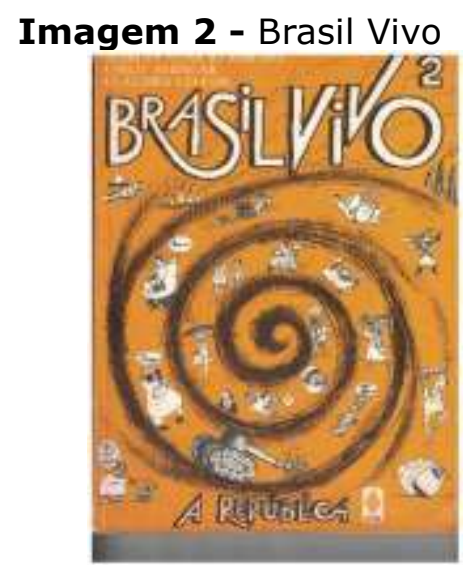

Fonte: Alencar, Ribeiro e Ceccon (1986-1988, v. 2). 
Imagens 3 - ilustrações de Claudius Ceccon

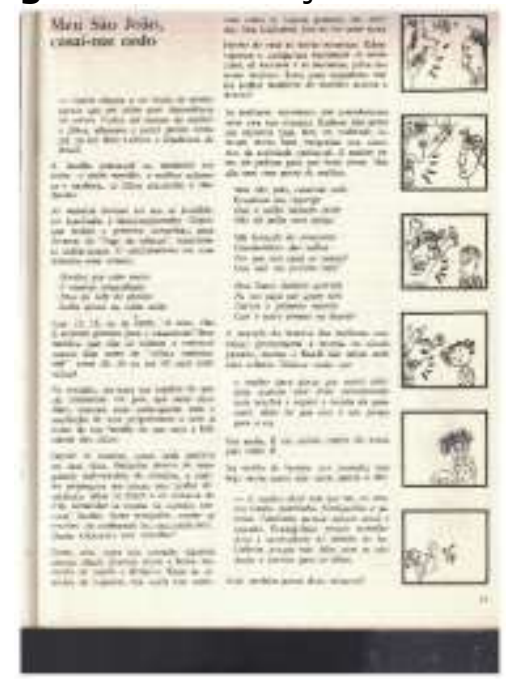

Fonte: Alencar, Ribeiro e Ceccon (1986-1988, v. 1, p. 33).

Imagem 4 - ilustrações de Claudius Ceccon

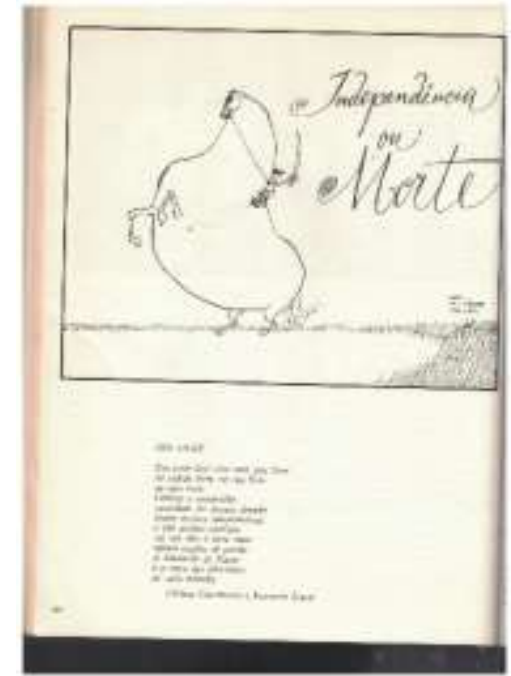

Fonte: Alencar, Ribeiro e Ceccon (1986-1988, v. 1, p. 64).

A coleção é bastante rica, abrindo interessantes possibilidades de análise. Somente os aspectos visuais dos livros mereceriam uma reflexão à parte, especialmente pelas ilustrações de Ceccon, que lançou mão do humor para subverter alguns valores e contar a história a partir de outros pontos de vista. Como destacou Kazumi Munakata (2007, p. 293), a diagramação do livro, associada à linguagem descontraída, lembrava muito produções como o Pasquim. A concepção do livro também trazia elementos valiosos, como a estratégia de iniciar todos os capítulos com letras de músicas de Milton 
Nascimento e Fernando Brant; $^{5}$ a opção por uma linguagem livre e repleta de "licenças poéticas"; e a incorporação, ao final de cada capítulo, de uma sessão intitulada "Brincando e aprendendo", que buscava retomar os conteúdos estudados a partir de propostas bastante criativas. Vale lembrar que questões relativas às representações da Inconfidência Mineira na coleção, ao papel que temas da cultura afro-brasileira e indígena ganharam ali, e aos elementos que a fazem se aproximar e se distanciar de outras obras didáticas do período, já foram objeto de estudos anteriores. ${ }^{6}$

O que pretendemos aqui é trabalhar aspectos mais gerais da obra que nos permitam entender as demandas sociais que incidiam sobre o ensino de história no contexto da redemocratização. Para isso, nos interrogamos se seria possível partir dessa coleção para pensarmos o que alguns setores sociais esperavam do ensino da história escolar num momento de profundas mudanças para a sociedade brasileira. Isso porque acreditamos que a maneira como os autores dessa obra compreenderam a história como conhecimento e a história entendida como ação dos homens no tempo pode nos dizer algo acerca dos papéis atribuídos ao ensino dessa disciplina em um contexto de mudanças políticas. Não se trata, evidentemente, de considerar que há uma conexão direta entre o contexto político subjacente à produção de Brasil Vivo e a narrativa desenvolvida ali pelos autores. Trata-se, antes, de inserir este livro didático no cenário em que foi produzido e ponderar que o processo de redemocratização trazia certas demandas sobre a história escolar, o que implicava não apenas interpretar o passado sobre novas bases, como também pensar novas possibilidades de futuro.

Se temos de entender essa demanda sobre os autores, não podemos esquecer também a expectativa dos leitores. Esse aspecto nos ajuda a considerar que a história, na sua dimensão de um conhecimento passível de ser ensinado, atende a certos fins pedagógicos e a demandas que são próprias do público para o qual ela se volta, o que lhe confere relativa autonomia em relação à história acadêmica. A autonomia que estamos considerando entre uma

${ }^{5}$ Segundo os autores de Brasil Vivo, os músicos Milton Nascimento e Fernando Brant gravariam um disco com as músicas que figuravam ao longo da coleção, e que seria lançado em seguida aos livros. Afinal de contas, segundo eles, "não basta contar a história do nosso povo. Mais que nunca, é preciso cantá-la também" (ALENCAR; RIBEIRO; CECCON, 1986, v. 1, p. 5).

${ }^{6}$ Essas análises foram levadas a termo por Fonseca (2001, p.91-122) e Moreno (2013). 
"história acadêmica" e uma "história ensinada" não deve ser entendia como sinônimo de desarticulação. O que estamos levando em consideração aqui é, por um lado, o papel criador da escola e do professor, cujas atuações são muito mais complexas do que uma mera reprodução de um saber acadêmico. Por outro lado, é preciso considerar também o público para o qual certas formas de escrever e narrar o passado se dirigem. Ao tratarmos de um livro didático, acreditamos ser fundamental atentar para o fato de que ele é produzido visando um tipo de consumidor específico, em muitos casos constituído por crianças e jovens, além de seus professores. Por conseguinte, a narrativa produzida ali atende a demandas próprias e necessárias à educação e aos interesses desse público. Pensar os livros didáticos dentro dessas balizas talvez nos ajude a ultrapassar as análises focadas em diagnosticar os "atrasos" desse tipo de produto cultural em relação à historiografia acadêmica (CHERVEL, 1990; TARDIF; RAIMOND, 2000). Assim, mais do que focarmos em conteúdos específicos e no tratamento que eles recebem por parte dos autores, nos interessa pensar as relações que eles estabelecem entre o leitor ao qual essa obra se destina e o passado contado por meio dos textos, letras de músicas e imagens.

É justamente essa conjugação de texto explicativo, letras de música e imagens de diversos tipos (fotografias, pinturas, charges) que confere ao livro uma narrativa bastante envolvente. Para isso, certos recursos são mobilizados pelos autores. O primeiro deles, como dito, é a irreverência, presente nas charges, ao longo do texto explicativo (que não hesita em contar certas piadas ou anedotas) e nos títulos e subtítulos dos capítulos, como aquele que trata da queda da monarquia e que recebeu o nome de "Caiu de madura". Essa irreverência e humor tinham claramente a intenção de distanciar a narrativa dos autores de um tipo de história denominada por eles como "cheirando a bolor", isto é, uma história "chata, factual, dos heróis e velha" (ALENCAR; RIBEIRO; CECCON, 1986, v. 1, p. 5). Aqui os autores lançam mão de uma dicotomia que é naturalizada quando se fala em ensino de história, sendo amplamente usada para estabelecer uma contraposição entre novas formas de ensinar história e um modelo genericamente chamado de "tradicional". Em contraposição a este modelo de história ensinada nas escolas, os autores propunham entender o passado brasileiro em novos termos, abrindo espaço para outros personagens, 
para projetos de país que não vingaram, para a história do tempo presente e para um futuro de incertezas. Uma história menos gloriosa, porém mais "viva", como consta, inclusive, no título da coleção. O humor, a anedota, o amor, a música e a arte, que fazem parte da vida, deveriam, segundo os autores, compor a narrativa. ${ }^{7}$

Mas essa narrativa envolvia outros artifícios que indicavam a preocupação dos autores com o público ao qual o livro se destinava (de jovens que cursavam o que chamamos hoje de anos finais do ensino fundamental, embora os autores não descartem a possibilidade da coleção ser utilizada entre um público adulto) e também com a abertura a novos personagens para compor o enredo dessa história. Mais uma vez, buscava-se uma narrativa que se contrapusesse àquela dos "grandes personagens do passado". A ideia era dar voz a outros grupos e agentes que compunham um núcleo esquecido dessa história ensinada. O primeiro deles é a criança, o ator central da coleção, bem como todo o universo que a rodeia, em especial a escola. Assim, em diversos capítulos, os autores introduziram personagens infantis fictícios ${ }^{8}$ e construíram situações em que contavam como crianças de outros tempos e de outras culturas (como as crianças indígenas ou as crianças do Brasil dos anos 1940) viviam e aprendiam.

Além da criança, o indígena, a mulher, o negro e o pobre também participam como protagonistas nessa história. A partir desses personagens, os autores abrem margem para tratar dos temas canônicos presentes há décadas nos livros didáticos, mas não esquecem também de aspectos do cotidiano e do problema da permanência de determinadas relações de poder na sociedade brasileira, como o racismo e o machismo. Todos esses agentes e grupos sociais constituíam-se como elos entre o presente e o passado. Eram representativos

7 Um exemplo nesse sentido pode ser visto logo no início da narrativa, no livro 1 de Brasil Vivo. No subcapítulo "Homem que é árvore, que é pedra, que é rio", faz-se uma caracterização geral da vida dos indígenas, em que se afirma "as proibições variam de acordo com a organização de cada tribo. Mas em muitas delas não há esse medo - bem nosso conhecido - em relação ao amor e ao sexo. Das margens do rio Guaporé, em Rondônia, vem a certeza dos nambikwara: - Tamindige Mondage! (fazer amor é bom!). (ALENCAR; RIBEIRO; CECCON, 1986, v. 1, p. 12).

8 Os autores mobilizam o recurso de tratar de algum tema sob o ponto de vista de personagens fictícios. Isso é feito, por exemplo, logo no primeiro capítulo do volume um, quando é contada a história de Tsipré, um indiozinho Xavante. A partir desse personagem, os autores caracterizam diversos aspectos da cultura daquele povo antes da chegada dos europeus à América. Outro momento em que os autores lançam mão dessa estratégia é no capítulo 12 (intitulado "Nosso tempo"), em especial no item "Gente sem terra". Aqui, vários personagens fictícios aparecem na narrativa para representar a realidade dos 40 milhões de brasileiros que viviam no campo (ALENCAR; RIBEIRO; CECCON. 1988, p. 11; 1986. v. 2, p. 248-249). 
também do descompasso da experiência do tempo para personagens diferentes e que viviam em espaços distintos. Mais do que isso, serviam para contar uma história "viva", "presente", em que a resistência do homem comum (a "nossa gente", presente no subtítulo da coleção) tomava o lugar da glória dos grandes homens. Assim, buscava-se escrever a história dos homens e mulheres de "mãos calejadas", dos trabalhadores das cidades, do retirante, dos camponeses, dos homens e mulheres do cangaço, todos eles presentes em Brasil Vivo. O elemento que alinhavava esses quase 500 anos de história era a resistência: a da liderança indígena que, como muitos de seus antepassados, foi assassinada em 1984 no Mato Grosso por defender "a sua gente" guarani em um conflito de terra; a dos negros que, de acordo com a narrativa proposta na coleção, continuavam a luta de Zumbi dos Palmares, Tonho Paciência e João Candido; a das mulheres que se espelham nas ações de Maria Quitéria, Bertha Lutz e Olga Benário.

Como lembraram Heymann e Arruti quando trataram das controvérsias em relação ao tema da memória comparando o caso francês e o caso brasileiro, é possível perceber aqui como esse fortalecimento da memória da resistência guarda relações metafóricas com a memória política da ditadura militar. No artigo em questão, os autores procuram analisar, numa perspectiva comparativa, as lutas sociais pelo reconhecimento e as disputas pela gestão da memória nacional no Brasil e na França. No caso brasileiro, é possível perceber a emergência do debate em torno da memória nacional a partir dos anos 1980 . Mas esse debate se desenvolveu em dois sentidos principais. O primeiro deles, por meio de uma demanda dos grupos vitimados pelo Estado brasileiro, trazendo à tona toda uma discussão em torno da violência secular sobre os índios e os negros. O segundo refere-se aos anseios dos grupos que sofreram a brutalidade da ditadura militar. De acordo com os autores, pelas características do processo de transição democrática brasileira, a violência contra negros e indígenas, que remetia ao passado colonial, foi a memória possível de ser evocada naquele momento (HEYMANN; ARRUTI, 2012, p. 96-119). Em Brasil Vivo, o ato de resistir, além de ligar passado e presente, conferia à história da gente brasileira alguma esperança frente a um futuro incerto que se abria com a redemocratização. A resistência que, para os autores, viria da criatividade mobilizada por crianças, negros, índios, homens e mulheres como arma de luta, 
abria, em todos os tempos, outras possibilidades de futuro, mesmo que a maioria delas tenha sido derrotada. Na perspectiva dos autores, tais experiências ensinavam na medida em que fortaleciam uma memória de luta da "gente brasileira".

Como se vê, a coleção Brasil Vivo pauta-se em algumas escolhas que envolvem a forma como se conta a história, que conjunto de experiências deve figurar em um livro didático e sob o ponto de vista de que agentes essa história deve ser contada. Esses elementos nos abrem a possibilidade de entender qual concepção de história é mobilizada pelos autores nessa obra e qual papel é atribuído ali à história escolar. Ou seja, para que (e para quem) essa história é contada/ ensinada. Entendemos que há aí duas questões interligadas, mas de ordens diferentes. No que se refere à maneira como os autores entendem o movimento histórico, eles lançam mão de uma interessante metáfora, que evidencia que aquela diferenciação entre uma história dos grandes homens e uma história da gente brasileira era mais do que um deslocamento metodológico, em que o historiador daria voz aos silenciados. Antes, envolvia toda uma maneira de compreender a própria história como ação dos homens no tempo. A metáfora é tirada de uma música de Chico Buarque e Pablo Milanez. A partir de dois versos dessa música, os autores perguntam ao leitor: "o que é a história: 'carroça abandonada numa beira de estrada' ou 'um carro alegre cheio de um povo contente'?". E eles mesmos respondem: "Isso depende de quem faz a história, de quem a sente. De quem conduz a carroça ou o carro". Mais adiante, retomam a questão, tornando mais claro seu ponto de vista:

\begin{abstract}
A história é como um carro sempre em movimento. É como a vida da gente, sempre em transformação. Alegre ou triste, o carro da história sobe, desce, avança, mas nunca para! Nossa vida, como a história, não segue um curso certo, em que todo mundo sabe exatamente o que vai acontecer (ALENCAR; RIBEIRO; CECCON, 1986 , v. 1, p. 55).
\end{abstract}

A metáfora da carroça e do carro é mobilizada pelos autores para propor uma percepção da história na perspectiva do movimento, das mudanças e permanências, dos avanços e dos progressos, dos erros e dos acertos. Como um carro, ela às vezes avança, às vezes dá marcha à ré, mas não para. Dependendo 
de quem a conduz, pode ser imprevisível. Acreditamos que esta metáfora empregada pelos autores pode ser tomada como uma síntese de uma das principais tarefas atribuídas ao ensino de história e das expectativas despejadas sobre essa disciplina no contexto de redemocratização. A metáfora do carro, além de explicar a percepção da história desses autores, pode nos ajudar a entender também que papel ele conferiram ao ensino da história nas escolas, uma vez que o estudo do passado entendido no plano dos avanços e recuos, certezas e incertezas, abria a possibilidade do leitor/ estudante entender a si mesmo e sua época como parte desse movimento. Nesse sentido, a resistência, para os autores uma característica marcante da gente brasileira, aparece ali não somente como chave de entendimento para o passado, mas como a ferramenta na construção dos futuros possíveis. Não por acaso, o segundo volume da coleção encerra essa narrativa da história do Brasil com um dado fundamental: no final dos anos 1980, o Brasil tinha 130 milhões de habitantes. Mais de metade dessa população era composta por jovens menores de 18 anos. Vinte e cinco milhões desses jovens viviam nas ruas. Para quê e a quem importava aprender sobre a história do país? Isso depende. Para os autores, aquela história cheirando a bolor e que mais parecia uma "carroça abandonada" não interessava a ninguém. Mas uma história que se queria "viva", que dava a voz a grupos e experiências diversas, pautada na noção de resistência, essa sim, ao que parece, poderia ao menos ensinar a esses milhões de jovens que representavam mais da metade da população brasileira que, pelas ações dos homens no tempo, as coisas poderiam mudar. Talvez para melhor, embora não houvesse garantias disso. Em todo caso, a mudança vinha por meio da ação e, nesse quesito, experiências do passado poderiam servir de inspiração para o presente, reatualizando, sob novas demandas sociais, o velho topos da história como mestra e sua função pedagógica.

O livro Brasil Vivo parecia querer ser uma alternativa no mercado de livros didáticos num momento em que a discussão e as disputas em torno do currículo de história traziam a demanda por novos materiais e narrativas. É com este tom de "novidade boa" que alguns jornais da época noticiaram a chegada deste manual. O Jornal do Brasil, que chegou a destinar algumas páginas de seu Caderno B para a discussão sobre livros didáticos, publicou em 15 de fevereiro 
de 1987 uma reportagem em que se referia a Brasil Vivo como uma "pequena joia" em matéria de livros voltados para o então chamado $1^{\circ}$ grau. ${ }^{9}$ Mas uma das críticas mais favoráveis veio de Lionel Fischer e foi publicada na edição do jornal O Globo de 23 de março de 1986. Em seu artigo, o colunista deixa bastante claro os motivos que o fez aplaudir a iniciativa da elaboração deste livro didático:

Em termos educacionais, Brasil Vivo representa, sem dúvida, uma revolução; não apenas devido à sua encantadora e original estrutura narrativa, mas também pela coragem com que se opõe à versão de certos fatos - hoje comprovadamente falsa -, o qual só contribuiu para deturpar a História e criar mitos que tenderam aos interesses das classes dominantes. [...] A linguagem empregada é atual e charmosa. [...] O lado poético também se faz presente: ao relatarem as lendas e canções indígenas e africanas, os autores revelam o lado sensível e criativo dessas duas culturas, normalmente desconhecidos ou desprezados. [...] Quanto à parte visual, o livro é simplesmente extraordinário. Claudius Ceccon, autor da maioria das ilustrações, comenta o texto [...] de forma tão engraçada, irônica e contundente que se torna uma peça decisiva nesse projeto, que pretende educar e divertir ao mesmo tempo (FISCHER, 1986).

Como se vê, a linguagem, a abertura para novos temas, a narrativa envolvente e sensível, bem como as imagens que não só ilustram, como ajudam a escrever a história que se conta, são elementos que, para Fischer, fazem da publicação de Brasil Vivo uma "revolução" - que acompanha, aliás, a renovação historiográfica da época. Entretanto, o colunista adverte:

Brasil Vivo, no entanto, pode gerar polêmicas. Os professores de história conservadores, os historiadores que sempre se colocam a serviço do poder, os estabelecimentos de ensino reacionários talvez não perdoem os autores desta obra, que reavaliaram nossa História do ponto de vista daqueles que realmente a fizeram e que dela sempre se viram excluídos. [...] Mas a obra, ao que tudo indica, acabará se impondo. Afinal, o Brasil de hoje é outro (FISCHER, 1986).

A polêmica, de fato, não demorou a chegar, indicando, portanto, que não havia consenso em relação à narrativa do passado brasileiro que deveria ser ensinada nas escolas. A Revista Senhor trouxe uma pequena resenha, porém bastante ácida, escrita por Nei Duclós sobre o livro, que foi considerado pelo

9 Jornal do Brasil (1987). 
crítico como "um filho retardatário do ufanismo das Diretas Já". Mas Duclós vai além nas suas considerações, e acrescenta:

\begin{abstract}
A primeira fase [sic] da apresentação já dá o clima e a euforia debiloide que impera no livro. "A História é como o ar que respiramos". Ou seja, esquema Rede Globo: o público não sabe nada e deve ser tratado como aluno do Mobral. Vamos parar com isso: o público está na frente, sabe mais do que qualquer professor de escola de segundo grau. Deve-se aproveitar as oportunidades de edição e levar em frente projetos mais arrojados. Senão, a indústria de sebos vai proliferar no país (DUCLÓS, 1986).
\end{abstract}

A crítica de Duclós não ficou sem uma resposta dos autores. Em carta encaminhada aos editores da revista, Marcus Ribeiro lembra que o livro Brasil Vivo, longe de ser um "filho retardatário do ufanismo", começou a ser escrito em 1981 e foi concluído dois anos depois. Quanto às demais críticas, o autor sustenta seu argumento justamente nos novos caminhos seguidos pela historiografia acadêmica do período e, claro, numa boa dose de ironia também:

O que dizemos - 'a história é como o ar que respiramos: está sempre presente, mesmo sem a gente perceber' - inspira-se em preocupações contemporâneas de grandes historiadores empenhados na criação de uma História Nova, no que diz respeito, sobretudo, a objetos, métodos e fontes. Poderíamos citar Marc Bloch - 'o historiador deve estar onde estiver a carne humana' -, mas é bem provável que o Sr. Duclós vá achar que Bloch era um tarado! Recorramos, então, sem metáforas, a Lucien Febvre, que, talvez, fique mais fácil: 'a história é o estudo cientificamente elaborado das várias atividades e das diversas criações dos homens $[\ldots]^{\prime}$. Digamos, ainda, que queremos caminhar juntos, acertando e errando, com todos aqueles historiadores e professores, que desejam uma história política moderna, em que sejam problematizadas não só as questões econômicas (boa parte da nossa historiografia e do nosso ensino críticos têm-se limitado a focalizar apenas os aspectos relativos à 'produção') e políticas (têmo-nos limitado a considerar o exercício do poder uma questão exclusiva do Estado), mas também os temas do cotidiano de todos os homens, em especial os jovens, pois é este, esclareçam ao 'crítico', o 'público' principal a que Brasil Vivo se destina (RIBEIRO, 1986, grifo do autor).

Se Lionel Fischer acertou quando disse que o livro Brasil Vivo traria polêmicas, errou quando apostou que a obra acabaria se impondo. Pelo menos no que se refere aos números, a coleção ficou longe de ser um grande sucesso 
editorial, vendendo cerca de 20 mil exemplares. Até onde pudemos apurar, a "joia" produzida por Alencar, Ribeiro e Ceccon teve uma circulação restrita, sendo utilizada, predominantemente, nas escolas de classe média alta da Zona Sul do Rio de Janeiro. ${ }^{10}$

\section{Considerações Finais: de Brasil Vivo para as demandas sociais em torno da história escolar no Brasil dos anos 1980}

Como lembra Manoel Salgado Guimarães (2003, p. 9-24), escrever sobre o passado envolve uma atividade muito mais complexa do que expressar um contexto fora dele. Isso porque a escrita da história é também resultado de disputas entre memórias e das lutas travadas no interior de uma sociedade pelos sentidos atribuídos ao passado. No momento de incerteza, de alegrias e de frustrações advindas dos avanços e recuos no processo de restabelecimento da democracia no Brasil, abriu-se espaço também para a discussão acerca do currículo de diversas disciplinas, dentre as quais a história. Além disso, aquele se tornava um momento propício para pensar qual o papel do ensino, de modo geral, e do ensino de história, especificamente, não só para a formação de uma sociedade democrática, como também para a longevidade da democracia no país. Como mostrou Laville em um texto bastante conhecido dos historiadores brasileiros, essa busca por novas narrativas não é algo exclusivo do contexto da década de 1980 no Brasil, mas ocorreu em momentos distintos, sob demandas diferentes, em diversos países, como Inglaterra, França, URSS e Alemanha, lugares em que a discussão em torno dos conteúdos de história a serem ensinados ganhou o debate público (LAVILLE, 1999).

Se um governo democrático era visto como a saída possível para os problemas do país (e para a construção de uma "nova" República), o debate sobre o que ensinar aos jovens também deveria ocorrer em bases democráticas, mobilizando diversos setores e movimentos sociais, como o movimento negro, indígena e das mulheres, que, na luta pela constituição de identidades e reconhecimento, trouxeram a história para o centro do debate, atuando fortemente em prol da formulação de uma legislação que atendesse a seus

10 Jornal do Brasil (1987). 
interesses e objetivos. O livro Brasil Vivo parece-nos um meio interessante e, em certa medida, exemplar, da incorporação dessas demandas sociais no ensino de história. Demandas essas que tiveram desdobramentos nas décadas seguintes, com a elaboração da Lei de Diretrizes e Bases, dos Parâmetros Curriculares Nacionais e da Lei 10.639/03, que tornou obrigatório o ensino da história e da cultura africana nas escolas, legislação que foi complementada, em 2008, com a obrigatoriedade também do ensino da história indígena (lei 11.645/08). Vale destacar como esse debate em torno das histórias a serem ensinadas nas escolas promoveu o desenvolvimento de materiais didáticos que contemplassem esses novos temas e agentes, que ganhavam espaço nas narrativas, além de ter impactado também as universidades, com a abertura de concursos destinados a disciplinas que passaram a fazer parte dos currículos dos futuros professores e pesquisadores, como História da África.

Como alguns autores têm evidenciado, esse impacto nas universidades trouxe frutos importantes nos últimos anos. Um exemplo disso foi o fortalecimento do ensino de história como um campo de estudos e de pesquisa para o historiador, o que favoreceu, inclusive, a abertura de linhas de pesquisa voltadas para esta temática no interior de alguns programas de pós-graduação. Em uma pesquisa desenvolvida recentemente, Helenice Rocha e Ricardo Pacheco trabalharam com os dados fornecidos pela Plataforma Sucupira para o ano de 2015 e ofereceram números que revelam esse movimento. No caso dos mestrados e doutorados acadêmicos, dos 61 programas cadastrados na plataforma, 8 tinham uma linha de pesquisa voltada para o ensino de história. No caso dos mestrados profissionais, no universo de 8 programas, 6 tinham uma linha voltada para o ensino. A isto, somam-se também os 12 mestrados profissionais em rede (ProfHistória), totalmente voltados para pesquisa na área do ensino da disciplina (ROCHA; PACHECO, 2016, p. 55). Ou seja, se as universidades brasileiras passaram por um processo de incremento dos programas de pós-graduação em história a partir das décadas de 1970 e 1980, a pesquisa de Rocha e Pacheco parecem indicar que, num movimento mais recente, as questões do ensino têm ganhado maior atenção por parte da comunidade de historiadores, movimento que, vale ressaltar, é visto também em outras áreas do conhecimento, como a Matemática, Física, Ciências, que também 
se abriram para a dimensão do ensino de suas disciplinas, não deixando essas questões a cargo somente das faculdades de educação (ROCHA; PACHECO, 2016, p. 62).

Assim, a nosso ver, se a década de 1980 não pode ser considerada uma "década perdida" para a produção historiográfica acadêmica, também não merece esse título em matéria de ensino de história. Tal perspectiva, no entanto, não dispensa certos cuidados para que não passemos da ideia de "década perdida" a outra, igualmente passível de críticas, que é a de que os anos 1980 (e também os anos 1990) representaram uma completa renovação em matéria de ensino de história (algo que é reafirmado na expressão "repensando o ensino de história", usada frequentemente em diversas publicações). Se é inegável que o ensino de história como campo de pesquisa se constituiu recentemente, também vale a pena olharmos com alguma desconfiança certas ideias naturalizadas, como, por exemplo, a de que foi a partir dos anos 80 que os historiadores passaram a se ocupar do ensino de história. Ou, ainda, a de que esta década teria posto em questão a chamada "história tradicional", abrindo espaço não só para novos temas, como também para o uso de recursos diferentes e metodologias avançadas para ensinar história nas escolas. Observando rapidamente a história da nossa disciplina, ela nos oferece muitos exemplos de historiadores que, ao longo dos séculos $\mathrm{XIX}$ e XX, atuaram fortemente nos debates em torno do ensino de história, trabalharam na elaboração de compêndios didáticos e suportes de divulgação do conhecimento histórico e já discutiam as possibilidades abertas pelas novas mídias e linguagens alternativas para o ensino dessa disciplina.

Mesmo sem desconsiderarmos a importância das últimas décadas do século XX para certa organização do ensino de história como objeto e como campo de estudos no Brasil, ${ }^{11}$ acreditamos que, ao nos interrogarmos sobre o ensino de história nesse contexto da redemocratização, é necessário pensar nas ambiguidades, isto é, da retomada de elementos de longa data recuperados sob novas bases nesse momento de debates em torno da democracia no Brasil. Como não reconhecer na ideia de "gente brasileira", presente na Coleção Brasil

\footnotetext{
11 Vale a pena lembrar aqui como essa discussão em torno do ensino de história se materializou em encontros importantes, como o Encontro Nacional Perspectivas do Ensino de História e 010 Encontro Nacional de Pesquisadores em Ensino de História.
} 
Vivo, toda uma tradição historiográfica interessada em pensar o "povo brasileiro"? Ou ainda, como não perceber ecos das ideias de autores como von Martius, Capistrano de Abreu ou Gilberto Freyre quando se debate o papel dos indígenas, dos negros e do branco europeus na formação do Brasil? ${ }^{12}$ Evidentemente, não queremos aqui estabelecer uma linha de continuidade sem rupturas entre esses autores (que possuem diferenças substanciais entre si) e o debate travado nos anos 1980 em torno da identidade nacional. Antes, queremos chamar a atenção para o problema em torno da contribuição das matrizes africana, indígena e europeia na formação da cultura e da história brasileiras, debate este que remete a toda uma tradição, mas que é aqui ressignificado a partir da reivindicação do direito à diferença, à afirmação e à inclusão social (HEYMANN; ARRUTI, 2012).

Considerando essas questões e atentando para essas ambiguidades, tentaremos ainda responder a uma última questão proposta no início desse texto: em matéria de história ensinada, teríamos ainda como buscar inspiração nas propostas levada a termo pelos anos 80 ? Parece-nos que sim, em especial se considerarmos o debate atual e empobrecedor em torno de questões relativas à educação e ao ensino promovido por grupos que defendem, por exemplo, uma escola sem partido, ou ainda a proposta de mudanças para o ensino médio promovidas recentemente pelo Ministério da Educação. Falar sobre cada uma delas demandaria outras reflexões. Mas vale a pena salientar muito rapidamente um aspecto, referente às próprias concepções de educação e de ensino mobilizadas pelos grupos que pautam o debate nessa área atualmente. A ideia de educar para uma sociedade democrática e, portanto, plural, e o compromisso em torno de uma educação que amplie a percepção de mundo, que envolva o debate e a participação de grupos sociais diversos e que promova os direitos humanos, tem perdido lugar para outra concepção de educação que é, para dizer o mínimo, conservadora e reafirmadora do que se aprende no seio da família ou dos grupos aos quais se pertence. É essa visão de educação mais restritiva que tem pautado o debate atualmente. Isso traz, evidentemente, implicações para o

12 A força do pressuposto da presença das três raças na constituição da história do Brasil fica ainda mais evidente no Artigo 26, parágrafo 40, da Lei de Diretrizes e Bases da Educação Nacional (lei 9.394/ 96), que afirma: "O ensino da História do Brasil levará em conta as contribuições das diferentes culturas e etnias para a formação do povo brasileiro, especialmente das matrizes indígena, africana e europeia" (BRASIL, 1996). 
ensino de história, em especial em função de abordagens que consolidaram nas últimas décadas para essa disciplina e pela sua característica de historicizar certas noções e valores comumente tratados como naturais. Há de se perguntar se daqui a algum tempo, talvez tenhamos de assumir, nós mesmos, o epíteto de "década perdida". Mas, como nos lembram os autores de Brasil Vivo, a história é imprevisível, se faz com avanços e recuos e, mais do que isso, se faz também com resistência.

\section{Referências}

ALENCAR, Chico; RIBEIRO, Marcus Venício; CECCON, Claudius. Brasil Vivo: uma nova história da nossa gente. Petrópolis: Vozes, 1986-1988. 2v.

AVILA, Arthur Lima. Indisciplinando a historiografia: do passado histórico ao passado prático, da crise à crítica. Revista Maracanan, Rio de Janeiro, n. 18, p. 35-49, jan./jun. 2018.

BRASIL. Lei n. 9.394, de 20 de Dezembro de 1996. Estabelece as diretrizes e bases da educação nacional. Brasília: Presidência da República, 1996.

CHALHOUB, Sidney; SILVA, Fernando Teixeira. Sujeitos no imaginário acadêmico: escravos e trabalhadores na historiografia brasileira desde os anos 80. Cadernos AEL, São Paulo, v. 14, n. 26, p.13-45, 2009.

CHARTIER, Roger. À beira da falésia: a história entre incertezas e inquietude. Porto Alegre: UFRGS, 2002.

CHERVEL, André. História das disciplinas escolares: reflexões sobre um campo de pesquisas. Teoria \& Educação, Porto Alegre, v. 2, n.2, p. 177229, 1990.

DE DECCA, Edgar. O silêncio dos vencidos. São Paulo: Brasiliense, 1981.

DOSSE, François. História e ciências sociais. Bauru: Edusc, 2004.

DUCLÓS, Ney. Brasil Vivo. Senhor, Rio de Janeiro, n. 261, mar. 1986.

FERREIRA, Marieta de Moraes. O ensino da história, a formação de professores e a Pós-Graduação. Anos 90, Porto Alegre, v. 23, n. 44, p. 2149, dez. 2016.

FICO, Carlos; POLITO, R. A história no Brasil (1980-1989): elementos para uma avaliação historiográfica. Ouro Preto: Ufop, 1992. 
FISCHER, L. Nova gente em nossa história: a descrição do Brasil sem sisudez. O Globo, Rio de Janeiro, 23 mar. 1986.

FONSECA, Thais Nívia de Lima. "Ver para compreender": arte, livro didático e a história da nação. In: Lana Mara de Castro; FONSECA, Thais Nívia de Lima. Inaugurando a história e construindo a nação. Belo Horizonte: Autêntica, 2001. p.91-122.

GOMES, Ângela de Castro. Questão social e historiografia no Brasil do pós-1980: notas para um debate. Estudos Históricos, Rio de Janeiro, n. 34, jul-dez 2004, p. 157-186.

GOMES, Angela de Castro. A invenção do trabalhismo. Rio de Janeiro: FGV, 2005.

GUIMARÃES, Manoel Luiz Salgado. A cultura histórica oitocentista: a constituição de uma memória disciplinar. In: PESAVENTO, Sandra (org.). História cultural: experiências de pesquisa. Porto Alegre: Editora da Universidade, 2003. p. 9-24.

HEYMANN, Luciana; ARRUTI, José Maurício. Memória e reconhecimento: notas sobre as disputas contemporâneas pela gestão da memória na França e no Brasil. In: GONÇALVES, Márcia; ROCHA, Helenice; REZNIK, Luís; MONTEIRO, Ana (org.). Qual o valor da História hoje?. Rio de Janeiro: Editora FGV, 2012. p. 96-119.

JORNAL DO BRASIL. Rio de Janeiro, 15 fev. 1987. Caderno B.

LAVILLE, Christian. A Guerra das Narrativas. Revista Brasileira de História, São Paulo, v.19, n.38, 1999.

MAIA, Carlos Alvarez. A crise da história e a onda pós-estruturalista. Revista Maracanan, Rio de Janeiro, n. 18, p. 35-49, jan./jun. 2018.

MORENO, Jean Carlos. Quem somos nós?: apropriações e representações sobre a(s) identidade(s) brasileira(s) em livros didáticos de história (19712001).2013. Tese (Doutorado) - Unesp, Assis, 2013.

MUNAKATA, Kazumi. Histórias que os livros didáticos nos contam, depois que acabou a ditadura no Brasil. In: FREITAS, Marcos. Historiografia brasileira em perspectiva. São Paulo: Contexto, 2007. p. 271-296.

NICOLAZZI, Fernando. Muito além das virtudes epistêmicas. O historiador público em um mundo não linear. Revista Maracanan, Rio de Janeiro, $\mathrm{n}$. 18, p. 18-34, jan./jun. 2018. 
ROCHA, Helenice; PACHECO, Ricardo. Quando o ensino vira tema de pesquisa: o ensino de história na pós-graduação em história. Anos 90, Porto Alegre, v. 23, n. 44, p. 51-83, dez. 2016

QUADRAT, Samantha Viz (org). Não foi tempo perdido: os anos 80 em debate. Rio de Janeiro: Sete Letras, 2014.

RAGO, Margareth. A "nova" historiografia brasileira. Anos 90, Porto Alegre, n. 11, jul. 1999.

REVEL, Jacques. Proposições: ensaios de história e historiografia. Rio de Janeiro: Eduerj, 2009.

RIBEIRO, Marcus Venício. [Carta ao editor]. Revista Senhor, Rio de Janeiro, 19 mar. 1986.

SAMARA, Eni de Mesquisa. As mulheres, o poder e a família: São Paulo no século XIX. São Paulo: Marco Zero, 1989.

SOUSA, Francisco. Escritas da história nos anos 1980: um ensaio sobre o horizonte histórico da (re)democratização. Anos 90, Porto Alegre, v. 24, n. 46, p. 159-181, dez. 2017.

SOUZA, Laura de Mello e. O diabo e a terra de Santa Cruz. São Paulo: Cia das Letras, 1986.

TARDIF, Maurice; RAIMOND, Danielle. Saberes, tempo e aprendizagem do trabalho no magistério. Educação \& Sociedade, Campinas, ano 21, n. 73, p. 209-244, 2000.

VAINFAS, Ronaldo. História cultural e historiografia brasileira. História: Questões \& Debates, Curitiba, n. 50, p. 217-235, jan./jun. 2009.

WHITE, Heyden. Meta-história: a imaginação Histórica do século XIX. São Paulo: Editora da USP, 1992. 